\title{
Eattoria (Solusi Pemasaran Restoran Dan Kafe) Di Warung Lumayan Sebagai Layanan Online Berbasis Android
}

\author{
Nino Catur Novrianto ${ }^{1}$, Ade Trio Avangki ${ }^{2}$, Qismi Widia Ningsih ${ }^{3}$, Zefid Frenda Fathoni ${ }^{4}$, Bambang \\ Bane Ray ${ }^{5}$
}

\begin{abstract}
Abstrak--Kuliner merupakan suatu hal yang paling sering dicari masyarakat. Warung Lumayan sebagai mitra kami yang memiliki usaha yang cukup besar. Tetapi terdapat suatu permasalahan dalam bidang promosi dan pelayanan. Untuk itu kami membuat aplikasi berbasis Android yang bisa membantu masalah promosi dan pelayanan. Android adalah Smartphone yang diperkirakan akan menjadi platfrom smartphone terpopuler menurut Indonesia consumer electronics report - Q1 2016[1]. Dengan aplikasi Eattoria para pengusaha khususnya di bidang kuliner sepeti restoran, kafe, dan warung kecil lainnya dapat mempromosikan tempat usahanya secara luas. Dengan adanya aplikasi Eattoria, Warung Lumayan lebih dikenal dimasyarakat luas. Warung Lumayan bisa mempromosikan menu makanan dan minuman tanpa harus membuat pamflet dan banner. Dengan Eattoria masyarakat/konsumen dapat lebih mudah mencari tempat kuliner yang diinginkan dengan aplikasi Eattoria mulai dari restoran atau kafe mewah hingga warung sederhana.
\end{abstract}

Kata Kunci-Eattoria, Kuliner, Android

\section{Pendahuluan}

$\mathrm{K}$ uliner merupakan suatu hal yang paling sering dicari masyarakat, terbukti semakin banyaknya restoran lokal maupun asing siap saji merambah di Indonesia. Hal tersebut mengindikasikan bahwa insentitas persaingan dalam bisnis restoran semakin kuat. Jenis restoran seperti ini umumnya berada di lokasi - lokasi yang strategis. Sementara restoran restoran tradisional atau lokal bercirikan lambat dalam pelayanan, relatif kalah bersaing dilokasi dimana terdapat restoran siap saji tersebut. Tampilan restoran semacam ini, mulai dari lokasi, jenis dan rasa makanan, penataan, sistim pelayanan, dan sebagainya membawa kesan bagi sebagian orang bahwa restoran tersebut mewah dan bergengsi.

\footnotetext{
${ }^{1}$ Nino Catur Novrianto adalah mahasiswa Program Studi Teknik Informatika Universitas Kajuruhan Malang (email: caturnovriantonino93@gmail.com)

${ }^{2}$ Ade Trio Avangki adalah mahasiswa Program Studi Teknik Informatika Universitas Kajuruhan Malang (email: adeetrio29@gmail.com)

3 Qismi Widia Ningsih adalah mahasiswa Program Studi Manajemen Universitas Kajuruhan Malang (email: gismiw@gmail.com)

${ }^{4}$ Zefid Frenda Fathoni adalah mahasiswa Program Studi Teknik Informatika Universitas Kajuruhan Malang (email: zefid97@gmail.com)

${ }^{5}$ Bambang Bane Ray adalah mahasiswa Program Studi Teknik Informatika Universitas Kajuruhan Malang (email: dreamfiendx@gmail.com)
}

Pada dasarnya, konsumen akan lebih mudah mengambil keputusan pembelian yang sifatnya pengulangan atau terus menerus pada produk yang sama. Apabila faktor - faktor yang mempengaruhinya berubah, maka konsumen akan melakukan pertimbangan kembali dalam keputusan pembeliannya. Jika dikaitkan dengan fastfood (siap saji), maka dalam proses pengambilan keputusan pembeliannya juga melalui beberapa tahap. Dimana proses keputusan pembelian tersebut berkaitan dengan beberapa keputusan, terutama keputusan tentang merek produk dan penjualan. Setiap merek atas produk dan penjualan suatu perusahaan, memiliki keunikan dan kekhasan tersendiri yang dapat ditemui adanya konsumen yang berpelilaku setia kepada penjual tertentu.

Warung Lumayan sebagai mitra kami yang memiliki usaha yang cukup besar tapi, terdapat suatu permasalahan dalam bidang promosi dan pelayanan. Selama ini promosi masih dilakukan secara manual atau offline mulai dari orang ke orang, brosur yang disebarkan di lingkungan sekitar Warung Lumayan dan pelayanannya juga masih secara manual atau offline sehingga usahanya tidak bisa berkembang lebih besar dan dikenal masyarakat luas.

\section{TINJAUAN PUSTAKA}

\section{Layanan Pemasaran Restoran Dan Kafe}

Promosi adalah suatu usaha dari pemasar dalam menginformasikan dan mempengaruhi orang atau pihak lain sehingga tertarik untuk melakukan transaksi atau pertukaran produk barang atau jasa yang dipasarkannya. Pemasaran adalah suatu proses sosial dan manajerial yang didalamnya individu dan kelompok mendapatkan apa yang mereka butuhkan dan inginkan dengan menciptakan, menawarkan dan mempertukarkan produk yang bernilai dengan pihak lain [2]. Selama ini banyak restoran masih kesulitan untuk mempromosikan tempat usahanya beserta menu yang disediakan. Sebagian banyak yang sudah mempromosikannya mulai dari menyebarkan brosur, memasang banner, ataupun promosi di media sosial. Biasanya promosi melalui media cetak memerlukan dana yang lumayan besar. Karena media sosial bukan tempat untuk mempromosikan suatu restoran maka respon dari pengguna media sosial sangat sedikit.

Untuk itu kami membuat aplikasi yang bisa membantu masalah promosi dan pelayanan, hal yang kami tawarkan dalam aplikasi Eattoria ini adalah mempermudah mempromosikan tempat usahanya 
dimasyarakat luas, jadi tidak perlu lagi menyebarkan brosur ataupun memasang banner yang memerlukan biaya yang besar. Dengan Eattoria, pengguna tidak perlu repot berkeliling jalan mencari tempat untuk berkumpul, makan, diskusi karena Eattoria sudah menyediakan fitur maps mencari tempat restoran, kafe, dan warung terdekat secara online. Pengguna juga bisa memberi feedback dan rating tentang restoran, kafe, dan warung yang telah dikunjungi pengguna. Aplikasi Eattoria menyediakan deskripsi menu yang ada di restoran, kafe, warung serta harganya dan pengguna bisa bookmark favorit restoran, kafe, restoran dan makanan minuman sehingga pengguna tidak perlu mencari lagi menu apa yang disukai pengguna, tinggal melihat dimenu bookmarks yang sudah disediakan di aplikasi Eattoria.

\section{Aplikasi Berbasis Android}

Android Studio [3] adalah Lingkungan Pengembangan Terpadu Integrated Development Environment (IDE) untuk pengembangan aplikasi Android, berdasarkan pada JetBrain IntelliJ IDEA Softwar (Lihat Gambar 1). Versi stabil pertama kali Android Studio dirilis pada desember 2014 sebagai pengganti Eclipse dengan (Android Development Tools) yang menjadi IDE utama pengembangan aplikasi android. Versi terbaru android studio saat ini yaitu versi 3.0 android studio sendiri mendukung sistem crossplatform yaitu dapat berjalan lingkungan sistem operasi baik di Windows, Linux, maupun Mac OSX. Selain itu aplikasi Android Studio juga berlisensi gratis sehingga dapat digunakan oleh siapa pun tanpa membeli atau mengeluarkan biaya.

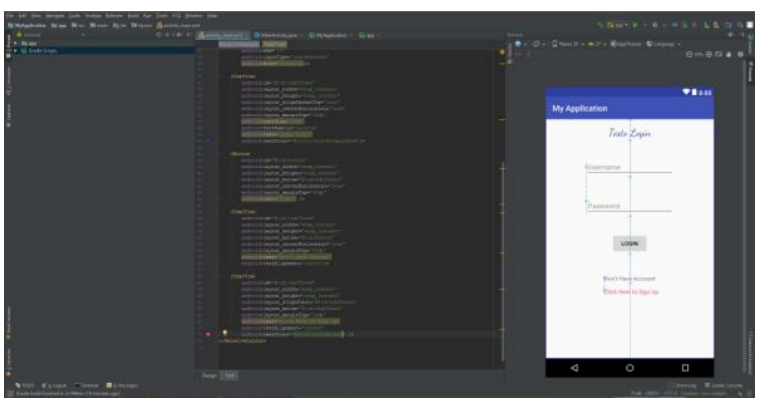

Gambar 1 Tampilan aplikasi Android Studio

Dalam pengembangan aplikasi Android melalui Android Studio, bahasa pemrograman yang digunakan adalah bahasa pemrograman Java. Hal ini di dukung dengan adanya komponen utama dari java yaitu JDK (Java Development Kit) yang menjadi lingkungan atau environment untuk menjalankan aplikasi yang dibuat dengan bahasa pemrograman Java [4].

\section{METODE PELAKSANAAN}

Metode pelaksanaan dari program ini secara garis besar di bagi menjadi 4 tahapan utama yakni:

1. Tahapan Pengembangan (Development)

Tahapan ini di bagi menjadi beberapa sub tahapan yaitu:

a. Analisis kebutuhan
Analisis kebutuhan di lakukan untuk memperoleh gambaran faktual mengenai kebutuhan layanan yang di perlukan oleh pengusaha dan konsumen mengenai aplikasi yang akan di kembangkan.

b. Penyiapan alat dan bahan

Penyiapan alat dan bahan dalam pembuatan aplikasi Eattoria meliputi:

$\circ$ Penyiapan alat (laptop, komputer, dan modem)

- Penyiapan bahan (penginstallan software aplikasi Android Studio, Visual Studio dan Emulator)

- Perancangan algoritma sistem aplikasi.

- Perancangan mockup UI (User Intefaces / Tampilan) aplikasi.

- Pembangunan backend server aplikasi secara online meliputi konfigurasi server web dan pembuatan basisdata.

$\circ$ Pembangunan frontend berbasis mobile (Android) dengan menggunakan program Android Studio.

- Melakukan testing secara internal (uji coba oleh tim peneliti / pengembang).

\section{Tahapan Publikasi (Production)}

Tahapan publikasi / production adalah tahapan di mana program aplikasi di publikasikan (Deploy) secara online, sehingga nantinya aplikasi akan dapat di unduh melalui Google Play Store oleh konsumen. Dalam tahapan ini beberapa hal yang dilakukan yaitu:

a. Melakukan pembelian akun google playstore

b. Melakukan pembelian layanan cloud computing

c. Mengkonfigurasi cloud computing / VMs (virtual machine) sesuai dengan spesifikasi kebutuhan aplikasi web dan basisdata.

d. Mengupload / melakukan deploying basisdata (Skema basisdata) serta data prefil (data awal user) ke layanan cloud computing.

e. Menerbitkan aplikasi Android ke Google Play Store.

f. Menguji coba aplikasi mobile (Android) dengan mengunduh dan install melalui Google Play Store.

3. Tahap Penerapan dan Implementasi

Pada tahap ini aplikasi yang telah jadi di terapkan pada layanan Eattoria.

a. Memberikan pemanduan / pelatihan penggunaan aplikasi Eattoria kepada pengusaha sebagai pengelola layanan / penyedia untuk konsumen.

b. Melakukan sosialisasi kepada konsumen tentang pengenalan aplikasi Eattoria, cara kerja aplikasi Eattoria, melalui jaringan sosial untuk konsumen dan pemanduan untuk konsumen.

4. Tahap Evaluasi dan Revisi (Penyempurnaan)

a. Tahap Evaluasi

Pada tahapan ini di lakukan pengevaluasian program aplikasi mulai penggunaan, kesalahankesalahan / error, dan feedback / masukan yang di berikan oleh pengguna, di mana hal ini yang akan di gunakan untuk melakukan revisi / penambahan fitur baru / perbaikan untuk menyempurnakan aplikasi di waktu selanjutnya. 
b. Tahap Revisi (penyempurnaan)

Tahap ini yaitu kita melakukan perbaikan dan penyempurnaan terhadap program aplikasi berdasarkan data hasil evaluasi. Seperti perbaikan bila terjadi error, penyempurnaan fitur -fitur tertentu agar lebih mudah, penambahan fitur-fitur baru, perbaikan tampilan, dan seterusnya.

\section{Implementasi Solusi Bersama Mitra}

Pada tahap implementasi ini, kami memandu Warung Lumayan untuk daftar merchant di aplikasi Eattoria Merchant. Pertama kami memandu Warung Lumayan untuk daftar merchant resto, kafe, warung tradisional. Kedua kami memandu Warung Lumayan untuk daftar user. Setelah itu Warung Lumayan login menggunakan user yang telah Warung Lumayan buat. Warung Lumayan bisa menambahkan menu makanan atau minuman, melihat daftar makanan atau minuman dan menghapus makanan atau minuman di Aplikasi Eattoria Merchant. Restoran kafe warung tradisional yang didaftarkan di aplikasi Eattoria Merchant, akan muncul pada aplikasi Eattoria.

Pada aplikasi Eattoria, bisa mencari restoran, kafe, warung tradisional dengan fitur pencarian dengan teks, pencarian restoran, kafe, warung tradisional dengan fitur kmaps lokasi terdekat dengan smartphone anda. Menampilkan menu restoran kafe warung tradisional. Aplikasi Eattoria ada fitur mencari rute dari lokasi smartphone ke lokasi restoran, kafe, warung tradisional yang sudah terintegrasi dengan Google Maps.

\section{Diagram Sequence}

Pada tahap ini merupakan tahap alur perancangan aplikasi dan alur aplikasi berjalan. Pada tahapan ini kami melakukan perancangan aplikasi berupa perancangan Diagram Sequence [5], dan perancangan antar muka (user interface). Berikut ini adalah Diagram Sequence aplikasi Eattoria dan Eattoria Merchant.

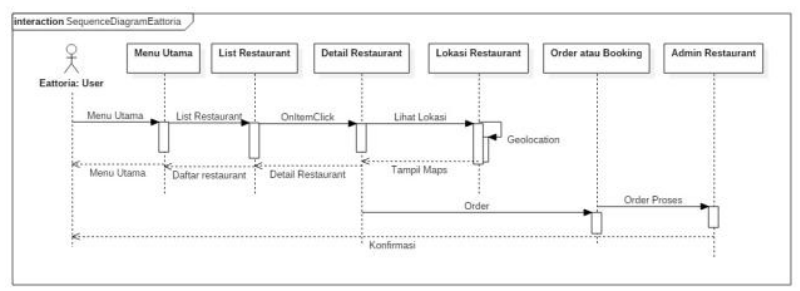

Gambar 2. Diagram Sequence Eattoria

Gambar 2 memperlihatkan menu utama aplikasi Eattoria yang berisi slide, search dan beberapa list horizontal. List restoran berisi list vertical restoran kafe warung tradisional. Detail Restoran menampilkan menu makanan, minuman, rating, booking.

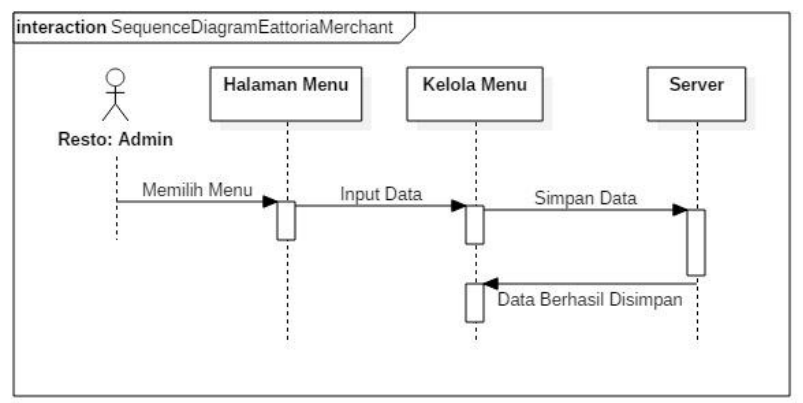

Gambar 2 Diagram Sequence Eattoria Merchant

Sedangkan di aplikasi Eattoria Merchant pada Gambar 2, ada Halaman Menu untuk menginputkan menu makanan minuman.

\section{HASIl Dan PEMBahasan}

Ada 2 aplikasi yang kami implementasikan ke mitra, aplikasi Eattoria sebagai aplikasi untuk menampilkan dan mencari kuliner, aplikasi Eattoria Merchant sebagai aplikasi untuk menginputkan data merchant restoran kafe warung tradisional dan data menu makanan muinuman. Kami memandu Warung Lumayan untuk menggunakan aplikasi Eattoria dan Eattoria Merchant mulai dari awal. Pertama kami mendaftarkan akun merchant di Eattoria Merchant.
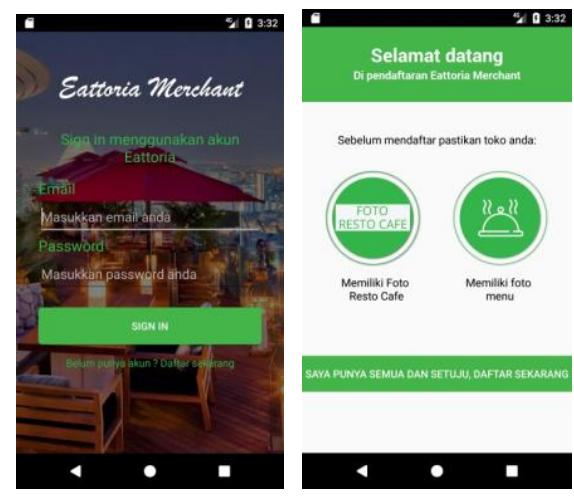

Gambar 3. Tampilan Login dan Welcome daftar Eattoria Merchant
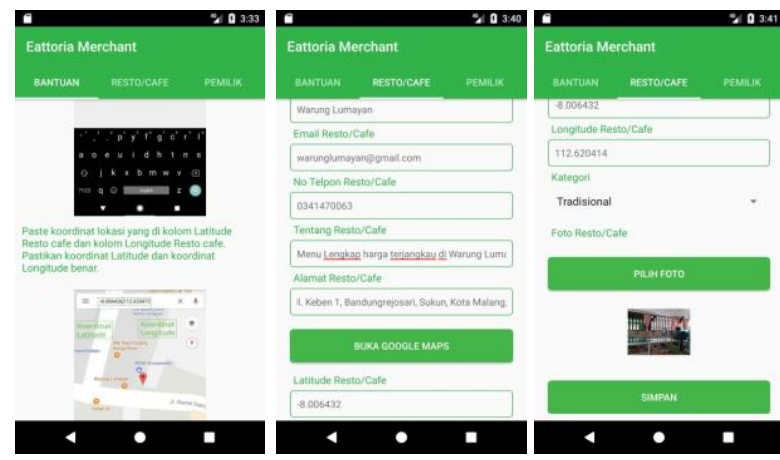

Gambar 4 Tampilan bantuan, daftar resto kafe dan daftar pemilik Eattoria Merchant

Gambar 3 dan Gambar 4, memperlihatkan layout bantuan/tutorial untuk daftar restoran kafe warung tradisional, cara memasukkan lokasi latitude longitude Google Maps. Layout Resto/Cafe untuk mendaftarkan restoran kafe warung tradisional ke database Eattoria. Ada kolom Nama Resto/Cafe, Email Resto/Cafe, No Telpon Resto/Cafe, Tentang Resto/Cafe, Alamat Resto/Cafe, Latitude Gmaps, Longitude Gmaps, 
kategori merchant, dan foto merchant anda. Tombol "Buka Google Maps" berfungsi untuk membuka aplikasi Google Maps yang berfungsi untuk mengambil koordinat Latitude dan Longitude, cara penggunaanya sudah ada di layout bantuan. Tombol "Pilih Foto" untuk memilih foto dari galeri atau file. Tombol Simpan untuk menyimpan data ke database Eattoria.

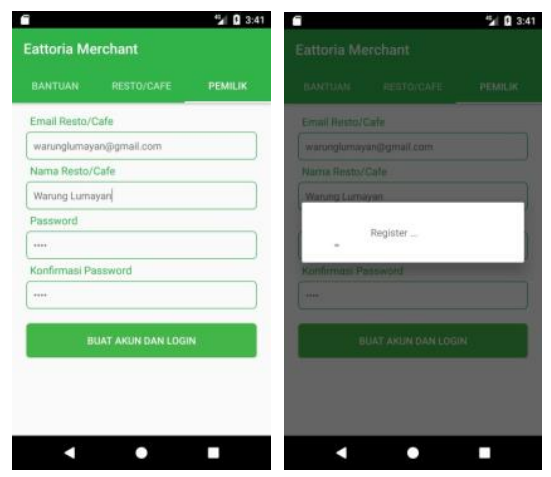

Gambar 5 Tampilan daftar pemilik atau user

Pada Gambar 5, tampilan daftar pemilik atau user. Ada kolom Email Resto/Cafe, Nama Resto/Cafe, Password dan konfirmasi password. Tombol "Buat Akun Dan Login" berfungsi untuk mengirimkan data yang di inputkan ke database Eattoria. Setelah data terkirim, akan pindah halaman ke Halaman Login. Login menggunakan akun yang sudah dibuat ditampilan daftar pemilik atau user. Setelah selesai, akan pindah halaman ke home Eattoria Merchant.

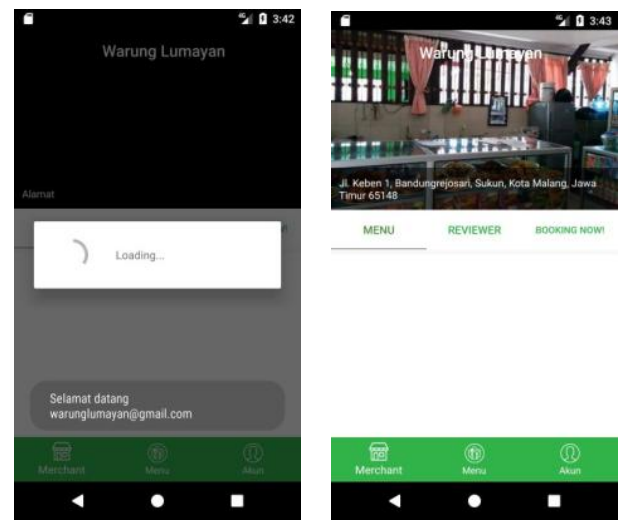

Gambar 6 tampilan home Eattoria Merchant

Gambar 6, pada home Eattoria Merchant untuk menampilkan menu makanan minuman yang sudah di inputkan user Eattoria Merchant pada tombol menu. Tombol menu berfungsi untuk menambahkan menu dan menghapus menu user Eattoria Merchant.
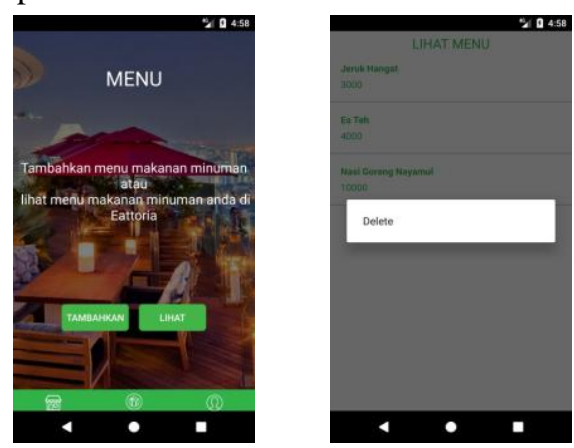

Gambar 7 tampilan menu Eattoria Merchant
Pada Gambar 7, tombol ditambahkan untuk menambahkan menu makanan minuman. . Sedangkan tombol lihat, untuk melihat menu makanan minuman user Eattoria Merchant, tampilan lihat menu ada list makanan minuman yang akan di hapus, tekan dan tahan menu yang akan di hapus, lalu muncul dialog delete, untuk menghapus menu.
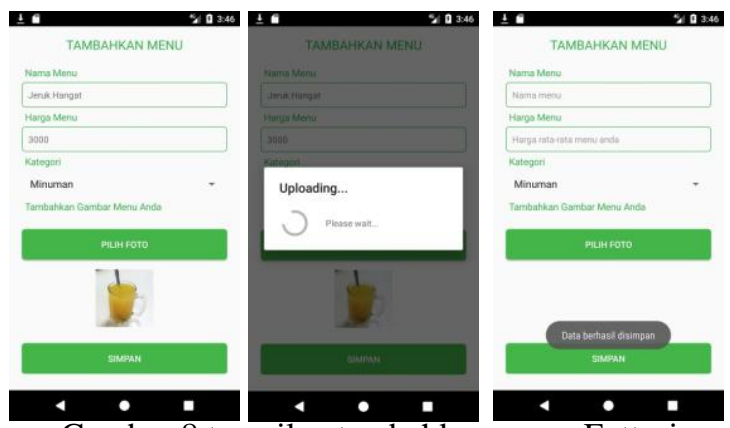

Gambar 8 tampilan tambahkan menu Eattoria

Merchant

Pada gambar 8, sama seperti di layout daftar restoran kafe merchant, untuk menyimpan data menu ke database Eattoria.
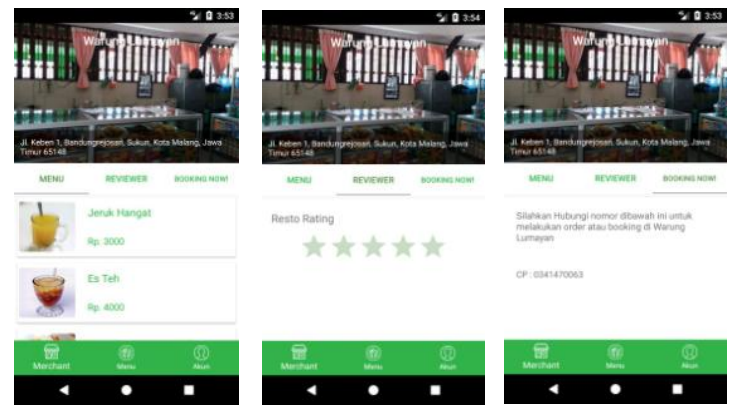

Gambar 9 layout home ada menu Eattoria Merchant

Gambar 9, Setelah tambah menu, menu akan tampil di home Eattoria Merchant. Di fragment Reviewer ada rating merchant, di fragment reviewer ada contact person merchant.
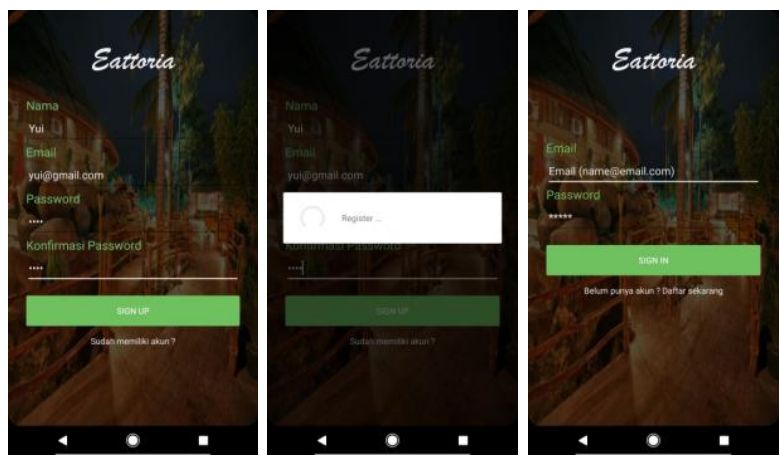

Gambar 10 tampilan daftar akun Eattoria

Gambar 10, untuk daftar akun Eattoria, text Sudah memiliki akun? untuk pindah ke layout login sesudah daftar akun. Login jika sudah daftar akun. 


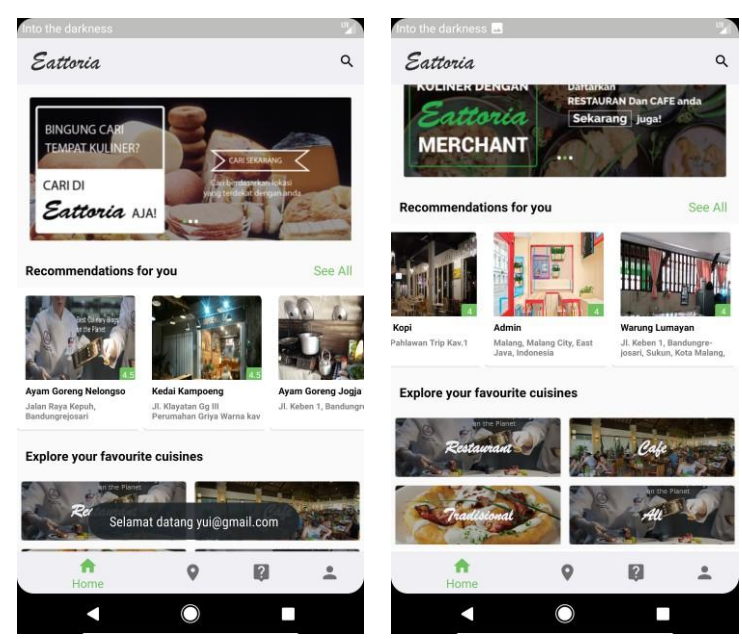

Gambar 11 tampilan home Eattoria

Gambar 11 merupakan tampilan home aplikasi Eattoria, icon search pada toolbar untuk mencari restoran kafe warung tradisional, icon lokasi untuk menampilkan restoran terdekat, icon help untuk bantuan cara menggunakan aplikasi Eattoria, icon akun untuk melihat nama akun, kebijakan privasi, ketentuan penggunaaan, gambar slide untuk menampilkan fitur baru atau berita tentang eattoria. ada list restoran kafe warung tradisional secara horizontal, tap nama restoran atau gambar akan pindah ke layout deskripsi restoran kafe warung tradisional. Teks See All untuk menampilkan semua restoran kafe warung tradisional secara list vertical.
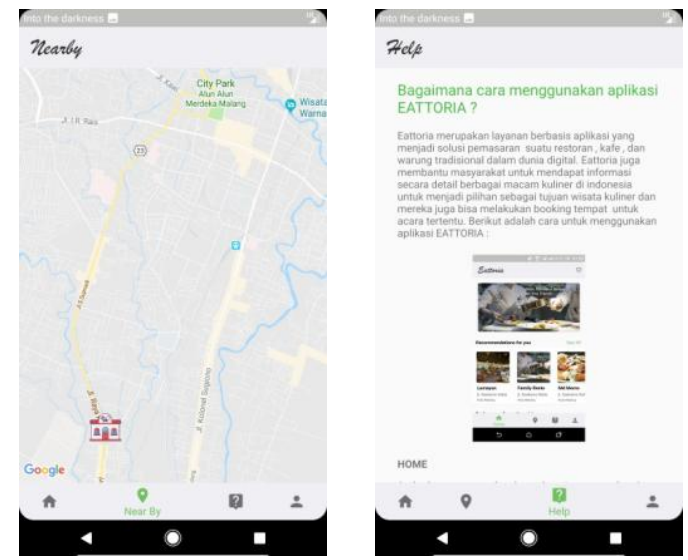

Gambar 12 tampilan restoran kafe dengan lokasi terdekat Eattoria dan tampilan help tutorial penggunaan Eattoria
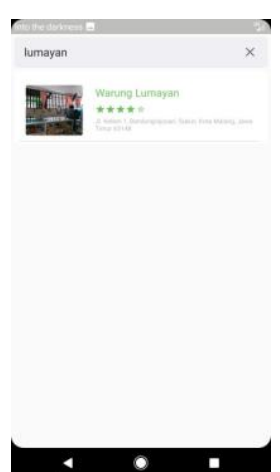

Gambar 13 tampilan pencarian restoran dan kafe warung tradisional Eattoria
Gambar 12 dan Gambar 13 memperlihatkan adanya kolom pencarian untuk mencari restoran kafe warung tradisional, hasil pencarian menjadi list vertical. tap nama restoran kafe warung tradisional akan pindah ke deskripsi restoran kafe warung tradisional.
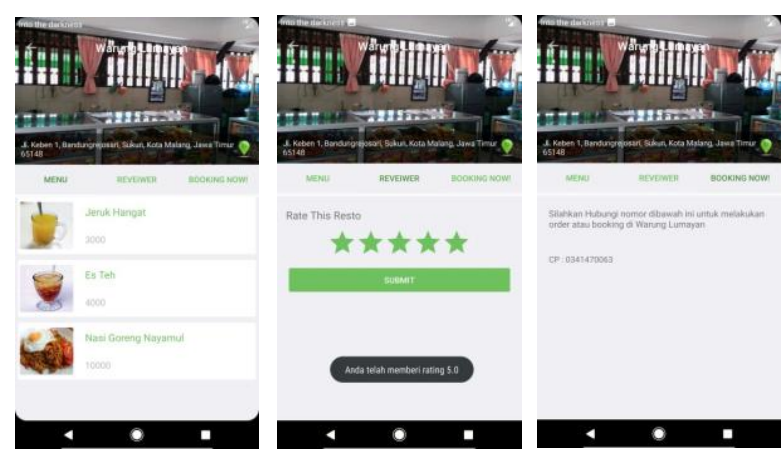

Gambar 14 tampilan deskripsi restoran dan kafe warung tradisional Eattoria

Gambar 14, sama seperti layout deskripsi di Eattoria Merchant, ada gambar restoran kafe warung, teks alamat restoran kafe warung, tombol lokasi untuk melihat lokasi restoran kafe warung berada. Pada $t a b$ menu menampilkan menu makanan minuman dari restoran kafe warung, tab reviewer bisa memberi rating restoran kafe warung, tab booking now! untuk menampilkan contact person restoran kafe warung.
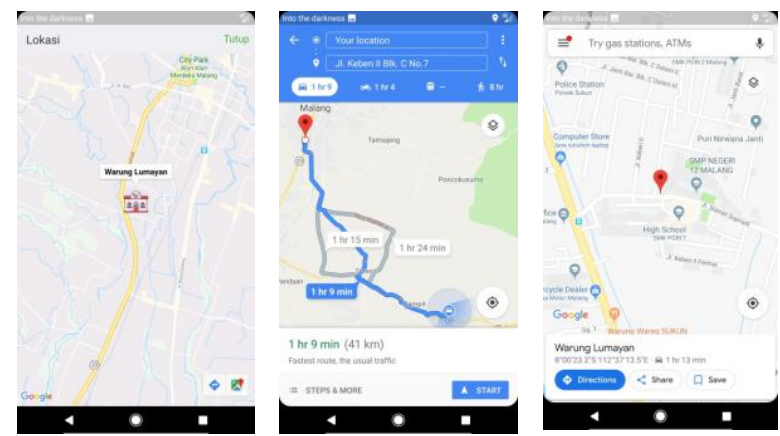

Gambar 15 tampilan lokasi restoran kafe warung tradisional Eattoria rute Google Maps menuju lokasi restoran kafe warung tradisional

Gambar 15, setelah di klik icon lokasi pada deskripsi toko, maka akan pindah ke layout maps lokasi restoran kafe warung. Icon rute untuk menunjukkan rute terdekat dari lokasi smartphone ke lokasi restoran kafe warung. Icon Google Maps untuk menujukkan lokasi restoran kafe warung di aplikasi Google Maps.

\section{KESIMPULAN DAN SARAN}

\section{Kesimpulan}

Berdasarkan analisa dan pengujian pada aplikasi "Eattoria (Solusi Pemasaran Restoran Dan Kafe) Di Warung Lumayan Sebagai Layanan Online Berbasis Android" maka dapat diambil kesimpulan sebagai berikut:

1. Aplikasi Eattoria ini berisi, berbagai macam restoran kafe warung tradisional, menu makanan minuman, lokasi terdekat smartphone dengan 
restoran kafe warung tradisional dan rute menuju restoran kafe warung tradisional.

2. Dengan aplikasi Eattoria para pengusaha khususnya di bidang kuliner sepeti restoran, kafe, dan warung kecil lainnya dapat mempromosikan tempat usahanya secara luas.

3. Masyarakat/konsumen dapat lebih mudah mencari tempat kuliner yang diinginkan dengan aplikasi Eattoria mulai dari restoran atau kafe mewah hingga warung sederhana.

4. Aplikasi Eattoria berbasis Android yang dapat diunduh di Google Playstore dan digunakan oleh semua orang.

\section{Saran}

Untuk pengembangan aplikasi "Eattoria (Solusi

Pemasaran Restoran Dan Kafe) Di Warung Lumayan Sebagai Layanan Online Berbasis Android" agar semakin bermanfaat bagi user ada beberapa hal yang dibisa dijadikan bahan kajian, yaitu:

1. Untuk kedepannya, disarankan ada fitur chat dan booking tempat di aplikasi Eattoria, agar user lebih mudah untuk booking tempat tanpa harus menggunakan aplikasi third-party.

2. Untuk kedepannya, disarankan bisa upload foto restoran kafe warung tradisional lebih dari satu foto, agar user mengetahui dengan jelas kondisi restoran kafe warung tradisional.

3. Untuk kedepannya, disarankan ada fitur otomatis saat pengambilan lokasi latitude longitude Google Maps, agar user lebih mudah saat penginputan lokasi latitude longitude Google Maps.

4. Untuk kedepannya, disarankan ada update data menu makanan minuman, update data profil dan delete akun.

\section{DAFTAR PUSTAKA}

[1] B. M. International, "Indonesia Consumer Electronics Report Q1 2016,” MarketResearch.com, 2015. [Online]. Available: https://www.marketresearch.com/BusinessMonitor-International-v304/Indonesia-ConsumerElectronics-Q1-9467539/.

[2] K. Philip, Marketing Management. Pearson Education Limited, 1997.

[3] Google, "Mengenal Android Studio," 2017. [Online]. Available: https://developer.android.com/studio/intro/index.html.

[4] M. V. Drongelen, "Android Studio Cookbook Design, debug, and test your apps using Android Studio," 1st Editio., Pact Publising Ltd, 2015.

[5] M. Grgec and R. Muzar, "ROLE OF UML SEQUENCE DIAGRAM CONSTRUCTS IN OBJECT LIFECYCLE CONCEPT,” J. Inf. Organ. Sci., vol. 31, no. 1, pp. 63-74, 2007. 